\title{
Stakeholder Perceptions of Specialized Accreditation by the Aviation Accreditation Board International: \\ Part Three - Level of Awareness and Perceived Value
}

\author{
C. Daniel Prather \\ Middle Tennessee State University
}

\begin{abstract}
In an effort to understand the current status of specialized accreditation in collegiate aviation and the reasons why so few aviation programs are accredited by the Aviation Accreditation Board International (AABI), a comprehensive study was undertaken to determine the perceptions held by the following four stakeholders of collegiate aviation regarding specialized accreditation by AABI: administrators of both AABI accredited and non-AABI accredited aviation programs, aviation program students, and aviation industry employers. This article is the third in a series of three reporting the results of this nationwide study.

Recommendations specific to part three of this nationwide study include: (a) AABI should develop a comprehensive marketing program aimed toward the various stakeholders of collegiate aviation, (b) AABI should seek enhanced collaboration with industry, and (c) AABI should explore the intrinsic merits of accreditation to truly determine how beneficial AABI accreditation is and the degree to which AABI is fulfilling its original purpose.

\section{INTRODUCTION}

As revealed in parts one and two of this study (see Prather, 2008a, 2008b), specialized accreditation allows for specific programs of study to be peer-reviewed and accredited, leading to enhanced visibility and prestige. In fact, many administrators in higher education expect their programs to achieve specialized accreditation if it is available (Council for Higher Education Accreditation, 2006; Wellman, 2003).

Yet, in collegiate aviation, specialized accredited by the Aviation Accreditation Board International (AABI) seems to be lacking in popularity (particularly among administrators of non-AABI accredited programs). Even though at the time of this study, there were 78 AABI accredited programs at 26 institutions of higher learning, only 26 percent of UAA member institutions had AABI accredited programs. Considering that there are at least 13 nonengineering collegiate aviation programs in the U.S. that are not institutional members of the

problems also exist in many academic fields with regards to low accreditation rates. Thus, collegiate aviation is not alone in this regard.

Nonetheless, this study was designed to determine why so few programs within collegiate aviation are accredited by the AABI. This paper, third in a series of three, presents the level of awareness and perceived value of AABI accreditation among four groups of stakeholders: administrators of AABI accredited and nonAABI accredited programs, collegiate aviation students, and aviation industry employers. The first article in this series presented a thorough literature review of the topic and examined the perceptions of AABI among collegiate aviation administrators. The second article examined the perceptions of collegiate aviation students and aviation industry employers regarding AABI accreditation. Understanding these perceptions will likely assist the AABI in strategically planning for the future by implementing measures to better meet the needs of collegiate aviation programs worldwide.
\end{abstract} UAA and many more worldwide, the actual percentage of institutions worldwide with $A A B I$ accredited programs is less than 26 percent. To be fair, although the actual percentage of accredited programs in many other academic fields is higher than in collegiate aviation,

\section{METHODOLOGY}

\section{Research Design}


This study utilized a non-experimental, mixed method research design, with both quantitative and qualitative attributes. The research design is a "mixed method" design in that both qualitative and quantitative data were gathered via cross-sectional surveys. Quantitative and qualitative data were collected via close-ended items and open-ended items on each questionnaire. In essence, this study is considered a descriptive study with data collection via cross-sectional surveys. Plainly, a "descriptive study simply describes a phenomenon” (McMillan, 2004, p. 176). [For further detail regarding the research design, the reader is encouraged to review Prather 2008a.]

\section{Instrument Design}

As detailed in Prather (2008a, 2008b), four original, researcher-designed questionnaires were created for this study: Survey of Administrators of AABI Accredited Programs, Survey of Administrators of Non-AABI Accredited Programs, Survey of Aviation Program Students on AABI Issues, and Survey of Aviation Industry Employers on AABI Issues. Each of these questionnaires was designed to measure perceptions about AABI accreditation, and included dichotomous items, as well as Likert-scale and open-ended items.

\section{Validity and Reliability of Measurement}

As explained by Alreck and Settle (1995, p. 58), "a measurement of any kind is valid to the degree it measures all of that and only that which it's supposed to measure." Face validity of the questionnaires was enhanced by informally allowing persons not involved in the study to review the questionnaires for accuracy and ease of completion, resulting in several revisions to the questionnaires. Content validity was enhanced by allowing a group of experts to review each of the questionnaires (Gay \& Airasian, 2000). This group of experts consisted of one member of the University Aviation Association (UAA), one member of the Aviation Accreditation Board International (AABI), and the researcher's supervisory committee chair. This jury was presented with an overview of the study and the purpose of the questionnaires. In adapting Litwack's (1986) method, each juror was asked to rate each question on a three-point scale of importance: 1-important; 2-important, but requires revision; 3-not important. Items rated by two out of three jurors as important or important, but requires revision, were included in the questionnaire. In addition to the ranking of items on a scale of importance, constructive comments were also received, resulting in additional questionnaire refinement.

In addition to a focus on validity, reliability was also addressed. Reliability, as explained by Alreck and Settle (1995, p. 58), means "freedom from random error." A fundamental test of reliability is that of repeatability (Alreck \& Settle, 1995). This survey was administered only once, as lack of resources and time did not allow for extensive test-retest methodology. However, McMillan (2004) explains that reliability of an instrument can be measured in terms of internal consistency via the Cronbach alpha, appropriate for instruments in which there is no right or wrong answer to each item. As seen in Table 1, the Cronbach's reliability coefficients for the four questionnaires ranged from 0.479 to 0.855 . As McMillan (2004) states, reliability coefficients of 0.65 are acceptable for measuring noncognitive traits, whereas studies of groups can tolerate a lower reliability, sometimes as low as 0.50 in exploratory research. Further, as suggested by McMillan, additional efforts were implemented to minimize the lower than desired internal consistency of this questionnaire. First, with each of these questionnaires, there were standard conditions of data collection, in which each of the four groups were provided the same directions. Also, the instruments were appropriate in reading level and language of the subjects. Lastly, the questionnaires were brief, thus not experiencing the problems associated with lengthy questionnaires.

In a final effort to address issues of validity and reliability, as well as pre-test the operation of each questionnaire, a pilot study was conducted. A main goal of this pilot study was to determine if the questionnaires were easily understood and could be completed within a reasonable time period. The pilot study consisted of five members randomly selected from each of the sample populations. Responses received from each group closely matched responses collected from each group during the full study. 
Table 1. Questionnaire Reliability

\begin{tabular}{|l|c|}
\hline \multicolumn{1}{|c|}{ Instrument } & $\begin{array}{c}\text { Cronbach } \\
\text { Alpha }\end{array}$ \\
\hline $\begin{array}{l}\text { Survey of Administrators of } \\
\text { AABI Accredited Programs, }\end{array}$ & 0.750 \\
\hline $\begin{array}{l}\text { Survey of Administrators of } \\
\text { Non-AABI Accredited } \\
\text { Programs }\end{array}$ & 0.546 \\
\hline $\begin{array}{l}\text { Survey of Aviation Program } \\
\text { Students on AABI Issues }\end{array}$ & 0.479 \\
\hline $\begin{array}{l}\text { Survey of Aviation Industry } \\
\text { Employers on AABI Issues }\end{array}$ & 0.855 \\
\hline
\end{tabular}

\section{STUDY POPULATIONS}

\section{Administrators of AABI \& Non-AABI Accredited Programs}

As detailed in part one of this series, administrators of AABI accredited and nonAABI accredited collegiate aviation programs were included in the study. The survey population (and sample) consisted of one department administrator (or chair) from each of the non-engineering aviation academic program departments that are located at the 23 institutions nationwide with AABI accredited programs (at the time of this study), as well as the 76 institutions nationwide with non-AABI accredited programs (utilizing the University Aviation Association institutional member list at the time of this study).

\section{Collegiate Aviation Students}

In addition to surveying administrators of collegiate aviation programs, the students of these programs were also included in the study. The collegiate aviation student survey population consisted of the total number of aviation students enrolled at all of the 112 institutions offering non-engineering aviation academic programs nationwide (UAA, 2003). Determining the sample frame for this large survey population was not very feasible. The sample frame, therefore, consisted of the student membership list of the UAA, and the sample included each of these 98 students.

\section{Aviation Industry Employers}

Lastly, aviation industry employers were included in the study in an effort to determine the role of AABI accreditation in hiring decisions. The goal was to include the various segments of the aviation industry, including national and regional airlines, cargo carriers, government agencies, airports, fixed base operators, and consulting firms. Surveying the entire survey population would have been prohibitive. Thus, the sample frame consisted of the membership lists of the following aviation industry trade groups: American Association of Airport Executives (720 airport members and 591 corporate members), Air Transport Association (18 airline members), National Air Transportation Association (2,000 associate members), and the National Business Aviation Association (6,000 corporate and associate members). A simple random sample of members from each of these groups was contacted. Randomly selecting 40 corporate members from each of these four organizations (with the exception of the entire 18 Air Transportation Association members), resulted in a total sample size of 138 industry employers. The questionnaire was then directed to the Director of Human Resources (or central hiring office) of each organization.

\section{SURVEY PROCEDURES}

The implementation of the questionnaires designed for this survey project closely adhered to Dillman's (2000) Tailored Design Method. Specifically, three contacts were made via firstclass mail, while the fourth and fifth contacts were made via e-mail and fax, respectively. Each of these five contacts was utilized for the purpose of increasing survey response rate. As Dillman (2000, p. 149) explains, "Multiple contacts have been shown to be more effective than any other technique for increasing response to surveys by mail." The first contact was made with recipients on June 22, 2007, and the final contact was made on July 30, 2007.

\section{DATA ANALYSIS}

As detailed in parts one and two of this study, both quantitative and qualitative data were collected as a result of implementing the non-experimental mixed method research design. The majority of quantitative data collected during this research study involved nominal and ordinal data. As a result, non- 
parametric statistical analyses were heavily relied upon in analyzing these quantitative data. SPSS version 15.0 and Microsoft Excel were the statistical analysis software used to analyze quantitative data collected during this study. Specifically, the chi-square test for goodness of fit was utilized to analyze nominal data. The Likert-scale ordinal data were analyzed using simple frequency distributions.

To analyze the qualitative data collected during this study, content analysis via a manual coding effort was employed. After comments were separated into the theme categories based on their general intent, the number of responses in each theme category was then counted numerically to allow general conclusions to be drawn from the qualitative data.

\section{Findings}

Part one in this series (Prather, 2008a) presented the perceptions of collegiate aviation administrators regarding specialized accreditation. Part two (Prather, 2008b) presented perceptions of aviation students and industry employers. In addition to the perceptions presented in parts one and two of this series, this third part allows one to understand the level of awareness of $\mathrm{AABI}$ and the perceived value of AABI accreditation among the four groups of stakeholders included in this research effort.

Research Question 10: Is there a relationship between administrators of AABI accredited and non-AABI accredited programs, collegiate aviation students, and aviation industry employers regarding their level of awareness of the AABI?

This research question was designed to determine the level of awareness among the four groups of stakeholders included in this study. Specifically, each of the four questionnaires contained the following identical item: "Prior to receiving this survey, I was unaware of the Aviation Accreditation Board International (AABI)." Participants were asked to rate their level of agreement with this statement on a fivepoint Likert scale. Because this item gathered ordinal data from four groups, the KruskalWallis test was used to determine if a relationship existed among the four groups regarding their level of awareness of the AABI.
As noted by Gravetter and Wallnau (2004, p. 650), "The Mann-Whitney test is limited to comparing only two treatments (or populations), whereas the Kruskal-Wallis test is used to compare three or more treatments (or populations).”

The null hypothesis of this test is similar to others previously presented in this study. In essence, there is no relationship among the groups on their level of awareness.

H0: There is no relationship between administrators of AABI accredited and nonAABI accredited programs, collegiate aviation students, and aviation industry employers regarding their level of awareness of the AABI.

The outcome of the Kruskal-Wallis test indicated significant differences among the four groups regarding their level of awareness of AABI, $H=77.602$ (3, $\mathrm{N}=139), \mathrm{p}<0.05$. With a critical region beginning at 7.81 at the 95 percent confidence interval, the decision was made to reject $\mathrm{H}_{0}$. Therefore, at the 0.05 level of significance, the data provide sufficient evidence to conclude that there is a significant difference among administrators of AABI accredited and non-AABI accredited programs, collegiate aviation students, and aviation industry employers regarding their level of awareness of the AABI.

The number of responses by each of these groups is graphically portrayed in Figure 1.

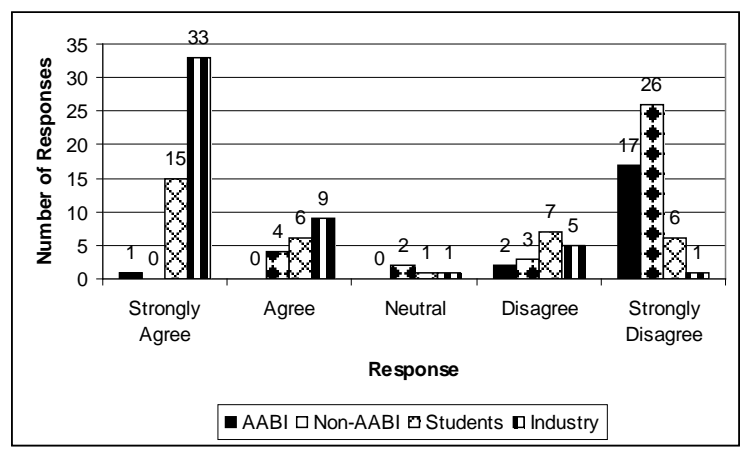

Figure 1. Level of AABI Awareness

Research Question 11: Is there a significant difference between administrators of AABI accredited and non-AABI accredited programs, collegiate aviation students, and aviation 
industry employers regarding their level of perceived value of AABI accreditation?

As the reader will recall, the main focus of this research effort was to determine why so few collegiate aviation programs are accredited by AABI. To answer this question, the perceived value of $A A B I$ was measured for each of the groups (administrators of AABI accredited programs, administrators of non-AABI accredited programs, collegiate aviation students, and industry employers). In essence, each of the four researcher-designed questionnaires included an item containing a 10 point scale that instructed participants to indicate, on a scale of 1 to 10 , how valuable they feel AABI accreditation is to collegiate aviation, students, or industry (depending on the population being surveyed). This item collected interval data and allowed for the only use of a parametric test during this study. The test chosen to analyze these data was the analysis of variance (ANOVA). The ANOVA was chosen because of its appropriateness to evaluate mean differences between two or more populations. For the purpose of this test, the following null hypothesis was developed:

$\mathrm{H}_{0}$ : There is no difference between administrators of AABI accredited and nonAABI accredited programs, collegiate aviation students, and aviation industry employers regarding their level of perceived value of $A A B I$ accreditation.

To evaluate mean differences, the mean of each group on the 10 point scale had to be determined. These means and standard deviations are shown in Table 2.

Table 2. Mean and Standard Deviation of Perceived Values of AABI Accreditation

\begin{tabular}{|l|c|c|}
\hline \multicolumn{1}{|c|}{ Group } & $\boldsymbol{M}$ & $\boldsymbol{s}$ \\
\hline AABI & 8.3684 & 1.8918 \\
\hline Non-AABI & 5.8571 & 2.5221 \\
\hline Students & 5.3428 & 2.7859 \\
\hline Industry & 3.3617 & 2.6327 \\
\hline
\end{tabular}

Note: 1 equates to no value, while 10 equates to high value. $M=$ mean; $s=$ standard deviation.

Figure 2 is a graphical representation of the frequency of responses to this scale.

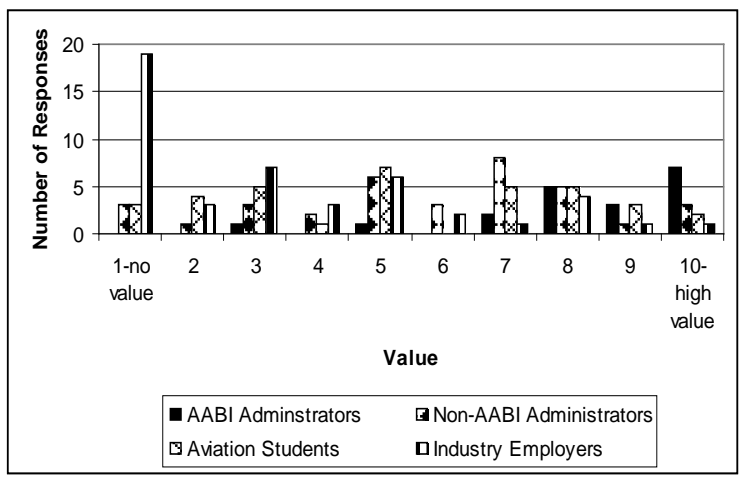

Figure 2. Perceived Value of AABI

Accreditation

Note: Columns represent the actual number of responses among each survey group for each of the ten levels of perceived value.

As seen in Figure 2, it would appear that industry employers generally perceive no (or very little) value in AABI accreditation; administrators of non-AABI accredited programs and collegiate aviation students perceive some value in $A A B I$ accreditation, while administrators of AABI accredited programs perceive high value in AABI accreditation. However, are these differences statistically significant? To determine this, a parametric test with an independent-measures design was necessary. Thus, a single-factor ANOVA was chosen to determine whether the observed sample mean differences are larger than expected by chance (Gravetter and Wallnau, 2004).

The analysis of variance revealed a significant difference, $F(3,132)=18.619$, $\mathrm{p}<0.05, r^{2}=0.297$. Thus, $\mathrm{H}_{0}$ is rejected (See Table 3). However, since we are comparing four group means, this result only indicates that there is at least one mean difference greater than would be expected by chance. To better understand which mean differences are significant and which are not, a Scheffe post hoc test was also performed on the data. The Scheffe test was chosen because as Gravetter \& Wallnau (2004, p. 428) explain, "Because it uses an extremely cautious method for reducing the risk of a Type I error, the Scheffe test has the distinction of being one of the safest of all possible post hoc tests." The Scheffe posttest indicates a significant difference exists between 
all groups, with the exception of between nonAABI administrators and students.

Table 3. ANOVA Summary Table

\begin{tabular}{|c|c|c|c|c|}
\hline SOURCE & SS & $d f$ & $M S$ & $F$ \\
\hline $\begin{array}{l}\text { Between } \\
\text { groups }\end{array}$ & $\begin{array}{l}365.37 \\
3\end{array}$ & 3 & $\begin{array}{l}121.79 \\
1\end{array}$ & $\begin{array}{l}18.61 \\
9\end{array}$ \\
\hline $\begin{array}{l}\text { Within } \\
\text { groups }\end{array}$ & $\begin{array}{l}863.44 \\
4\end{array}$ & $\begin{array}{l}13 \\
2\end{array}$ & 6.541 & \\
\hline Total & $\begin{array}{l}1228.8 \\
16\end{array}$ & $\begin{array}{l}13 \\
5\end{array}$ & & \\
\hline
\end{tabular}

\section{DISCUSSION}

As previously stated, determining the perceived value of AABI accreditation was a major goal of this study. As determined by the statistical analysis of the data related to research question 11, a significant difference was discovered among the four groups surveyed regarding their perceived value of AABI accreditation. Specifically, administrators of AABI accredited programs registered the highest perceived value (8.3684), while aviation industry employers registered the lowest perceived value (3.3617). Collegiate aviation students and administrators of non-AABI accredited programs shared the middle ground (5.3428 and 5.8571, respectively). This finding is not only important, but interesting as well, in that lack of awareness was only an issue among collegiate aviation students and industry employers.

These findings lead one to question the degree to which AABI has fulfilled its original purpose. As previously noted (Prather, 2007), AABI recognizes seven specific purposes. Although this study did not specifically address whether the standards actually did meet the needs of the various stakeholders, on the surface, it appears that $\mathrm{AABI}$ is generally fulfilling these seven purposes. However, although AABI has accomplished curriculum standardization within collegiate aviation, it is clear that not all stakeholders want AABI accreditation for the various reasons AABI has outlined. The lack of demand from students and industry for AABI accredited programs further complicates the issue. Indeed, non-AABI accredited programs generally feel successful at what they do and there is no requirement that students graduate from an AABI accredited program (as in other fields where national certification/licensure tests require the applicant to have graduated from an accredited program).

When measuring the level of awareness of $\mathrm{AABI}$, administrators of both AABI and nonAABI accredited programs appear well aware of AABI. However, the level of awareness seems to stop at the doors of academia, or more specifically, at the office doors of administrators in the aviation program. Students, for instance, were generally unaware of AABI. More disconcerting, however, was the very low level of awareness among industry. What are the meanings of these findings? In essence, if there is no demand for $\mathrm{AABI}$ accreditation from the constituents of collegiate aviation programs, there will be little demand for AABI accreditation among these aviation programs. For if future college students don't seek out AABI accredited programs and industry is not demanding graduates of AABI accredited programs, "What's the use?" as one administrator stated. Clearly, without demand for AABI accredited aviation programs by students and industry, the main reason a program would seek AABI accreditation is for self-improvement. In other words, would someone spend all the time and effort necessary to acquire a doctoral degree if, upon completion, it was only recognized by the individual's immediate family? This is doubtful; yet, this is to some degree the position AABI and collegiate aviation is in today. AABI accreditation seems to be recognized only by academia, that close group of administrators and faculty of collegiate aviation programs. However, the goal of AABI and collegiate aviation programs accredited by AABI should be to spread the good news of AABI accreditation far and wide, so that prospective students, current students, industry, the general public, and the general academic community are aware of AABI accreditation and the many benefits derived there from.

In addition to the assumptions previously discussed that were challenged by these findings, the results of the study also challenged current thought in other areas as well. For instance, although administrators of AABI accredited programs indicated a high level of agreement with statements presented in the 
questionnaire as to why their program decided to initially seek and maintain AABI accreditation, it appears from findings elsewhere in the study that some of these beliefs may be erroneously held. For instance, 95 percent of responding administrators of AABI accredited programs indicated they sought and maintained AABI accreditation "to ensure that the program meets standards established by the profession." However, 85.8 percent of responding industry employers were not even aware of AABI prior to receiving the survey. Likewise, 32.0 percent of responding industry employers feel AABI does not offer any direct or indirect benefits to industry. Thus, if industry is unaware of AABI and questions its benefits, how is industry establishing standards for collegiate aviation programs? A likely answer would be the AABI Industry-Educator forum. Each summer, AABI invites industry (in the form of an Industry panel) to offer challenges to educators. These challenges typically spell out industry requirements in certain areas and the need for graduates to posses certain skills, knowledge, and abilities. Subsequently, educators present a response to industry at each AABI Winter meeting. Clearly, some of these findings make their way into AABI standards or criteria. However, one criticism is that many of these findings do not, and more importantly, the industry challenge is presented by a mere handful of industry representatives (that already are, or soon become, aware of AABI). Thus, AABI should consider whether the IndustryEducator Forum has sufficient industry support and adequately reflects industry concerns, resulting in AABI accredited programs having "standards established by the profession."

When explaining why they sought and continue to maintain AABI accreditation, administrators of AABI accredited programs also strongly agreed with the following statement: "To help attract and recruit highly qualified students and faculty." Although this research effort did not include faculty within the four population groups, it did address collegiate aviation students. In choosing which program to attend, only 8.6 percent of responding students indicated AABI accreditation status as having any bearing on that decision. When specifically asked if it was important for the student to attend a program accredited by AABI, only 20 percent of students responded in the affirmative. Lastly, 60 percent of students indicated a lack of awareness of AABI. Thus, it appears that AABI accreditation does not help to "attract and recruit highly qualified students." To rectify this situation, AABI should better market its efforts, including the purpose of specialized accreditation and the derived benefits, to high school students and high school guidance counselors. In essence, students need to be "captured" prior to their making a decision about which institution and aviation program to attend. Many comments were received during this and previous research efforts indicating that students (either future or current) rarely ask if a particular aviation program is accredited by AABI.

Similarly, based on the student responses previously detailed, it would appear that the belief that AABI accredited programs sought and maintain AABI accreditation "to assist potential students in selecting a quality training program," is also an error in judgment. In fact, with so few students aware of AABI and even fewer considering the AABI accreditation status of a program important in selecting an institution to attend, the aviation program accredited by AABI does little to "assist potential students in selecting a quality training program." The solution to this issue also involves more aggressive marketing by AABI to the many potential collegiate aviation students intending on pursuing an aviation career. Likewise, however, AABI accredited programs have a role to play in making sure that students considering their program are well aware of AABI, in terms of the standards the program has met, and the benefits of attending an AABI accredited program.

Another area of concern is that 80 percent of responding administrators of AABI accredited programs agree that their program initially sought and maintains AABI accreditation to "identify for employers those programs which have successfully met the profession's standards of preparation." However, as previously mentioned, industry employers to a great degree are unaware of AABI and place little, if any, emphasis on hiring graduates of AABI accredited programs. Thus, how does an AABI accredited program identify itself as a program 
having met the profession's standards of preparation? Once industry becomes aware of $\mathrm{AABI}$ and places a value on programs with accreditation by AABI, this issue should resolve itself.

A final area of concern involves the strong level of agreement among AABI accredited programs, when explaining why they sought and maintain AABI accreditation, with the following statement: "To gain the confidence of the educational community, related professions, and the public." Although the study did not focus on the educational community (with the exception of administrators of collegiate aviation programs), it focused on related professions (in terms of industry employers), and the public to some degree (in the form of collegiate aviation students). As detailed earlier, collegiate aviation students and industry employers are generally unaware of $\mathrm{AABI}$ and place minimal value on AABI accreditation. Thus, it would appear a mistaken belief for an AABI accredited program to believe it is gaining the confidence of related professions and the public. This issue can be resolved by better educating the educational community (including other academic fields), related professions, and the public as to the role AABI plays in ensuring excellence in collegiate aviation.

\section{RECOMMENDATIONS}

Aviation Accreditation Board International

1. Due to the lack of industry and student awareness of AABI discovered in this research effort, the organization should develop a comprehensive marketing program aimed toward the various stakeholders of collegiate aviation. By adopting this recommendation, industry may begin to realize the benefits of AABI accreditation, subsequently improving industry's perceived value of AABI accreditation and the emphasis industry places on hiring gradates of AABI accredited programs. Likewise, by educating high school students and high school guidance counselors as to the purpose and benefits of specialized accreditation, AABI can increase the awareness of AABI accreditation among potential aviation students. In essence, students need to be "captured" prior to their making a decision about which institution and aviation program to attend.

2. AABI should seek enhanced collaboration with industry. As part of this, AABI should consider whether the Industry/Educator Forum has sufficient industry support and adequately reflects industry concerns, resulting in AABI accredited programs having "standards established by the profession." This recommendation stems from the contrasting views among AABI accredited programs and industry regarding the benefits of AABI to industry. One criticism voiced by collegiate aviation administrators is that only a small segment of the industry regularly participates in the I/E Forum. Obviously, this must be addressed if this important component of $\mathrm{AABI}$ is to achieve all that it is intended to achieve.

3. AABI should explore the intrinsic merits of accreditation to truly determine how beneficial AABI accreditation is and the degree to which AABI is fulfilling its original purpose. This recommendation stems from the strongly contrasting views among collegiate aviation programs regarding the benefits of AABI accreditation and the apparent success of non-AABI accredited programs.

\section{AREAS FOR FURTHER RESEARCH}

Due to limited resources, this study did not include faculty members of collegiate aviation programs, the general public, and related industry employers. It would have been helpful to survey faculty members to determine, if in fact, they were attracted to an AABI accredited program because of its AABI accreditation status, or conversely, do not feel there are adequate benefits for the cost and time involved for accreditation among non-AABI accredited programs. Is the general public aware of specialized accreditation in general, and of AABI accreditation in particular? If so, what effect does that have on the visibility of a particular aviation program and the confidence 
the general public has in such a program? Additionally, are other industries aware of the specialized accrediting organizations in their academic field? Are other industries aware of AABI accreditation? For instance, some collegiate aviation students enter fields other than aviation upon graduation. Are related, but non-aviation industry employers (such as the Federal Highway Administration, Microsoft, or General Motors) aware of AABI? Lastly, future research could be conducted on this topic utilizing different samples of collegiate aviation students and industry employers. For instance, this study did not survey any airport managers, nor did it include students who are not student members of UAA.

Another area for further research would involve a comparison of the competencies possessed by graduates from both AABI accredited and non-AABI accredited programs. This would likely involve a subjective measurement of the quality of graduates, including how well prepared these graduates are for industry, by surveying those employers hiring graduates of collegiate aviation programs. It would be interesting to discover whether AABI accredited programs are indeed producing more successful graduates with enhanced industry skills and a broader knowledge base. If so, one could then make a case that if industry awareness of this fact increased (due to greater marketing by AABI for example), demand among industry employers for graduates of AABI accredited programs would increase, thereby likely having a positive effect on the number of non-AABI accredited programs interested in pursuing AABI accreditation for the benefit of their future graduates.

Yet another area for future research involves a deeper look at non-AABI accredited programs. Since administrators of non-AABI accredited programs generally disagreed with the eight statements included in the questionnaire targeting their reason for not having pursued AABI accreditation, more research is needed with this group to more clearly determine the reasons why their programs are not accredited. Although qualitative data were gathered in this area during this project, their disagreement with all of the provided statements did not allow for a beneficial quantitative analysis of their responses. Perhaps future research can incorporate the qualitative responses gathered in this study into close-ended statements to which respondents would then be asked to indicate their level of agreement or disagreement.

Additionally, since it is quite possible that the perspectives of many administrators and faculty will change now that AABI has transitioned from content-based standards to outcomes-based criteria, it will be helpful to duplicate this study to determine what effects if any, these new AABI criteria have on the level of interest shown by collegiate aviation programs toward AABI accreditation. It would seem that a study conducted five years in the future would be sufficient, as programs that were recently accredited or affirmed for reaccreditation would have completed a self study and navigated the accreditation process under the new criteria by that time. One must be careful if duplicating this study five years into the future, however. Specifically, as the researcher measures the perceived value of AABI accreditation, if improvements are seen (especially in the eyes of students and industry employers), it may be the result of more aggressive marketing by $\mathrm{AABI}$, for instance. If this is indeed the case, the study can determine which recommendations from the current study were followed and then attempt to measure the effects those implemented recommendations have had on the stakeholders of collegiate aviation.

Lastly, research could be conducted that seeks to determine from non-AABI accredited program administrators and faculty what their needs are, in regards to academic quality and specialized accreditation of collegiate aviation programs. Findings from this research could then be used by AABI to better meet the needs of those programs that have not sought AABI accreditation.

\section{CONCLUSION}

Although recommendations to AABI should naturally flow from these findings, it is prudent to discuss the changing landscape of accreditation in general, and of specialized accreditation by AABI in particular. In essence, 
substantial changes are now in effect that will greatly affect the manner in which collegiate aviation programs endeavor toward AABI accreditation, and subsequently the manner in which AABI reviews programs for accreditation. Simply, these changes involve a transition from content-based standards to outcomes-based criteria. As a result, the specialized accrediting environment has changed. No longer must collegiate aviation programs offer specific courses in a specific sequence to meet AABI standards. Today, these programs must develop learning outcomes for each aviation concentration the institution wishes to accredit through AABI. These learning outcomes, although historically a part of the higher education landscape to some degree, now must be formalized. Programs must develop learning outcomes for their entire program (to include both aviation courses and general education courses), devise methods of assessment to be certain these learning outcomes are being achieved, and then collect evidence to show (an AABI Visiting Team, for example) the level to which these learning outcomes have been achieved and the manner in which students are being prepared to be successful in the aviation industry.

How will this changing landscape in specialized accreditation affect the perceived value of AABI accreditation and the number of collegiate aviation programs accredited by AABI? Obviously, that is a question this research effort did not attempt to answer. However, based on discussions the author has had in the past with collegiate aviation program administrators, and comments collected from these individuals in this research effort and Prather (2006), more programs will be interested in pursuing $\mathrm{AABI}$ accreditation due mainly to the greater degree of flexibility the new AABI criteria offer. For instance, programs pursuing AABI accreditation under the former contentbased standards were required to include a calculus course within their aviation program degree requirements. In speaking with program administrators, at least two programs had not pursued AABI accreditation in the past because of this single requirement. In essence, they would have been forced to revise their general education requirements to include the calculus requirement. However, under the new AABI criteria (Aviation Accreditation Board International, 2007, p. 14), programs must only ensure "a combination of college level mathematics and basic sciences appropriate to the program." Although it is unknown at this time, it is possible that more programs will pursue AABI accreditation in the future solely because of the flexibility offered in the new outcomes-based criteria. It is this flexibility inherent in the new criteria that will likely allow AABI to newly accredit collegiate aviation programs that had, in the past, not pursued AABI accreditation. Even so, however, this study has highlighted the need to raise awareness of $\mathrm{AABI}$ and enhance the perceived value of AABI accreditation among the stakeholders of collegiate aviation. 


\section{REFERENCES}

Alreck, P. L. \& Settle, R. B. (1995). The Survey research handbook: Guidelines and strategies for conducting a survey. Chicago: Irwin Professional Publishing.

Aviation Accreditation Board International. (2007). Accreditation Criteria Manual. Retrieved October 25, 2007, from http://www.aabi.aero/Forms\&Pubs/ AABI201AccreditationCriteriaManualRev7-20-07.pdf

Council for Higher Education Accreditation (2006). An overview of U.S. accreditation. Washington, DC: Author.

Dillman, D. A. (2000). Mail and internet surveys: The tailored design method (2 ${ }^{\text {nd }}$ ed.). New York: John Wiley \& Sons.

Gay, L. R., \& Airasian, P. (2000). Educational research: Competencies for analysis and application ( $6^{\text {th }}$ ed.). New Jersey: Prentice-Hall.

Gravetter, F. J., \& Wallnau, L. B. (2004). Statistics for the behavioral sciences, (6 ${ }^{\text {th }}$ ed.). Belmont, CA: Thomson Wadsworth.

Litwack, K. P. (1986). Specialized accreditation of baccalaureate nursing programs in the United States. Unpublished doctoral dissertation, Kent State University.

McMillan, J. H. (2004). Educational research: Fundamentals for the consumer ( $4^{\text {th }}$ ed.). Boston: Pearson.

Prather, C. D. (2006). The council on aviation accreditation: Part two - Contemporary issues. Journal of Air Transportation, 11(3), 34-60.

Prather, C. D. (2007). Specialized accreditation in collegiate aviation: An analysis of the perceived value of specialized accreditation by the Aviation Accreditation Board International (Doctoral dissertation, University of Nebraska, 2007). Available at http://digitalcommons.unl.edu/cehsdiss/18

Prather, C. D. (2008a). Stakeholder perceptions of specialized accreditation by the Aviation Accreditation Board International: Part one - Collegiate aviation administrators. Collegiate Aviation Review, 26(1), 94-110.

Prather, C. D. (2008b). Stakeholder perceptions of specialized accreditation by the Aviation Accreditation Board International: Part two - Aviation students and industry employers. Collegiate Aviation Review, 26(2), 69-77.

University Aviation Association. (2003) Collegiate Aviation Guide. Auburn, AL: Author.

Wellman, J. V. (2003). Accreditation and the credit hour. New Directions for Higher Education, 122, 57-69. 